\title{
Motor vehicles are weapons of destruction
}

\author{
Driven to Kill: Vehicles as Weapons \\ J. Peter Rothe \\ University of Alberta Press; 2008. \\ 246 pp $\$ 34.95$
}

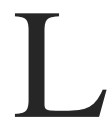

et's start with some word association. I say, "Automobile." You say, "The demise of GM." I say, "Car." You might reply, "Hybrid. Or Tata Nano, the cheapest car in the world manufactured in India." A lot of our conversation and media reportage of "automobility" tends to be about automobile production and consumption, innovation or ecological consequences. J. Peter Rothe thinks about vehicles differently.

In Driven to Kill: Vehicles as Weapons, he associates cars and trucks with "homicide, road rage, carjacking, drive-by shootings, smash and grabs, hit and runs, police chases, auto theft, auto break-ins." From the opening pages of his provocative and meticulous examination of roadway violence,

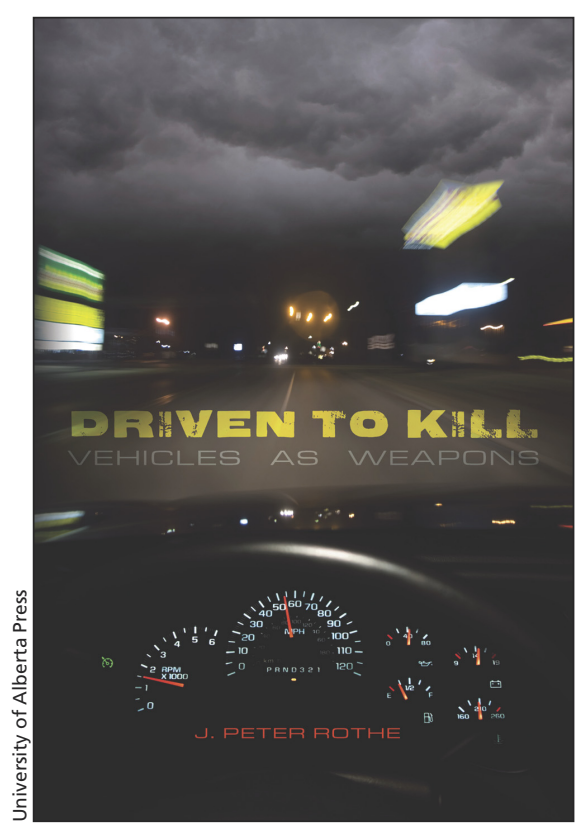

Safety Summit '98 that he edited. His research subjects have included older drivers, young drivers, truckers, motorcyclists and Aboriginal communities. Presently, he is an associate professor

\section{In 2005, the homicide death rate in the United States was 4.7 per 100 ooo people while the motor vehicle accident death}

\section{rate was I5.7 per IOO OOO.}

he questions the popular assumption of "vehicle violence as naturally occurring traffic safety accidents or normal events." He reframes vehicular violence as a major public health issue, - with ramifications that go far beyond isolated motor vehicle crashes.

Readers may be familiar with some of Rothe's earlier works, including Driving Lessons: Exploring Systems That Make Traffic Safer - a collection of essays by presenters at the Traffic at the University of Alberta School of Public Health and a senior researcher at the Alberta Centre for Injury Control and Research. His passion for public safety manifests itself in systematic research and iconoclastic thinking particularly with regard to the symbolic meanings that motor vehicles have for North Americans. Driven to Kill took five years to write.

Rothe points out that in 2005 , the homicide death rate in the United States was 4.7 per 100000 people while the motor vehicle accident death rate was 15.7 per 100000 . He believes that a significant number of these autocentred deaths and injuries result from driver-related acts of aggression, that vehicular violence "is a common subset of an increasingly violent society."

Violence on the road arises out of "a complex interplay of four major factors: the person, situation, vehicle and culture." To help us think clearly about the indirect and direct relationships of automobiles and violent behaviour, Rothe proposes a continuum of "zones of relevance" between the two. Vehicles can be tangential accessories to violent crimes (a means of transportation to and from crime scenes, or the scene of the crime). They can be blunt instruments of terror, revenge, suicide or murder.

Stylistically, the book is a hybrid - part journalism, part scholarly analysis. By heightening the documentary quality of the book, Rothe hopes to reach as wide an audience as possible. To emphasize the pervasive socio-cultural elements of vehicular violence, his research materials included accounts from print media and the Internet, court case transcripts and medical examiners' files. The stories may be sensationalized by the press, but Rothe's analysis is incisive and his arguments dispassionate. $\mathrm{He}$ is determined to raise public awareness and challenge contemporary vehicle ideology. Roadway violence is not normal: Although often misunderstood and undetected, it is criminal and destructive of the public good. The violent acts, along with their causes and consequences, need to be considered in that light, he argues.

What remains then is the usual Herculean task of changing public policy. Cars have been around for a century; seat belt legislation is a scant 20 years old. Reducing vehicular violence will 


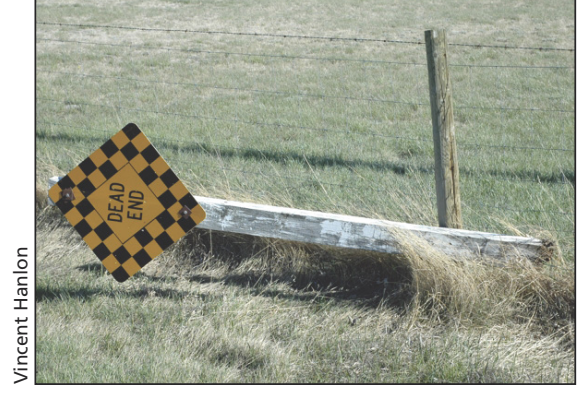

require a lot more work than the considerable effort that went into "buckling up."

The task of quantifying the diverse manifestations of roadway violence is not easy. Rothe quotes the John Howard Society's contention that nearly 70 per cent of violent crime goes unreported. Because "traffic safety is linked to the social context," Rothe calls for the psychological and social antecedents of crashes to be investigated more thoroughly than is presently done.

In outlining a public policy agenda Rothe also asks us to pay more attention to "the community of significant others" related to potential aggressors. Road rage, vehicular suicide and homi- cide demand more study. The links between departments of justice and transportation need to be firmed up. And when will we stop glamourizing perpetrators of roadway violence on television and in films and video games? The road ahead is long. Rothe is a good companion for the journey.

\section{Vincent Hanlon MD \\ Assessment physician \\ Alberta Medical Association \\ Physician and Family Support \\ Program \\ Lethbridge, Alta.}

